\title{
THE INFLUENCE OF REGIONAL SPINAL CORD HYPOTHERMIA ON TRANSCRANIAL MYOGENIC MOTOR-EVOKED POTENTIAL MONITORING AND THE EFFICACY OF SPINAL CORD ISCHEMIA DETECTION
}

S. A. Meylaerts, MD

P. De Haan, MD

C. J. Kalkman, MD, $\mathrm{PhD}^{\mathrm{a}}$

J. Lips, MSc ${ }^{\mathrm{a}}$

B. A. De Mol, MD, $\mathrm{PhD}^{\mathrm{b}}$

M. J. Jacobs, MD, PhD
Objective: Myogenic motor-evoked responses to transcranial electrical stimulation (transcranial myogenic motor-evoked potentials) can rapidly detect spinal cord ischemia during thoracoabdominal aortic aneurysm repair. Recent evidence suggests that regional spinal cord hypothermia increases spinal cord ischemia tolerance. We investigated the influence of subdural infusion cooling on transcranial myogenic motor-evoked potential characteristics and the time to detect spinal cord ischemia in 6 pigs. Methods: Regional hypothermia was produced by subdural perfusion cooling. A laminectomy and incision of the dura were performed at $\mathrm{L} 2$ to advance 2 inflow catheters at L4 and L6, to cool the lumbar subdural space with saline solution. Two temperature probes were advanced at L3 and L5, and 1 cerebrospinal fluid pressure line was advanced at L4. Spontaneous cerebrospinal fluid outflow was allowed. Spinal cord ischemia was produced by clamping a set of critical lumbar arteries, previously identified by transcranial myogenic motor-evoked potentials and lumbar artery clamping. The time between the onset of ischemia and detection with transcranial myogenic motor-evoked potentials (amplitude $<25 \%$ ) was determined at cerebrospinal fluid temperatures of $37^{\circ} \mathrm{C}$ and $28^{\circ} \mathrm{C}$. Thereafter, the influence of progressive cerebrospinal fluid cooling on transcranial myogenic motor-evoked potential amplitude and latency was determined. Results: The time necessary to produce ischemic transcranial myogenic motor-evoked potentials, after the clamping of critical lumbar arteries, was not affected at moderate subdural hypothermia $(3.8 \pm 0.9 \mathrm{~min})$ compared with subdural normothermia $(3.2 \pm 0.5 \mathrm{~min} ; P=.6)$. Thereafter, progressive cooling resulted in a transcranial myogenic motor-evoked potential amplitude increase at $28^{\circ} \mathrm{C}$ to $30^{\circ} \mathrm{C}$ and was followed by a progressive decrease. Response amplitudes decreased below $25 \%$ at $14.0^{\circ} \mathrm{C} \pm 1.1^{\circ} \mathrm{C}$. The influence of cerebrospinal fluid temperature on transcranial myogenic motor-evoked potential amplitude was best represented by a quadratic regression curve with a maximum at $29.6^{\circ} \mathrm{C}$. In contrast, transcranial myogenic motor-evoked potential latencies increased linearly with decreasing subdural temperatures. Conclusions: Detection of spinal cord ischemia with transcranial myogenic motor-evoked potentials is not delayed at moderate subdural hypothermia in pigs. At a cerebrospinal fluid temperature of $28^{\circ} \mathrm{C}$, transcranial myogenic motor-evoked poten-
From the Departments of Surgery, Anesthesiology a and Cardiopulmonary ${ }^{\mathrm{b}}$ Surgery, Academic Medical Center, University of Amsterdam, Amsterdam, The Netherlands.

This work was performed at the Department of Experimental Surgery, Academic Medical Center, University of Amsterdam, Amsterdam, The Netherlands.

Supported by the Dutch Heart Association, grant 97-193.

Received for publication Dec 29, 1998; revisions requested March 2, 1999; revisions received April 21, 1999; accepted for publication Aug 17, 1999.
Address for reprints: M. J. H. M. Jacobs, MD, PhD, Department of Surgery, Academic Medical Center, University of Amsterdam, Meibergdreef 9, Amsterdam 1105 AZ, The Netherlands (Email: M. Jacobs@amc.uva.nl).

J Thorac Cardiovasc Surg 1999;118:1038-45

Copyright @ 1999 by Mosby, Inc.

$0022-5223 / 99 \$ 8.00+0 \quad \mathbf{1 2} / \mathbf{1} / \mathbf{1 0 2 2 8 7}$ 


\section{tial amplitudes are increased. Further cerebrospinal fluid temperature decreases result in progressive amplitude decreases and latency increases. (J Thorac Cardiovasc Surg 1999;118:1038-45)}

$P$ araplegia is a complication of surgical repairs of thoracoabdominal aortic aneurysms (TAAAs). The incidence varies between $1 \%$ and $40 \%$, depending on the extent of the aneurysm, dissection, rupture, and crossclamp time. ${ }^{1}$ Protective strategies attempt to reduce the occurrence of this complication by either maintaining adequate spinal cord perfusion or increasing the spinal cord ischemia tolerance. .,3 $^{2,3}$

Monitoring spinal cord function during TAAA repair allows selective modification of surgical technique or application and adjustment of protective measures. Somatosensory-evoked potentials (SSEPs) are widely used for spinal cord function monitoring. However, their use is limited by false-negative results and a relatively long delay between the onset of spinal cord ischemia and detection. ${ }^{4}$ Monitoring of transcranial myogenic motor-evoked potentials (tc-MEPs) during TAAA surgery allows immediate detection of anterior horn ischemia, and no false-negative results have been described to date. ${ }^{5,6}$

Regional hypothermia is a promising technique to protect the spinal cord against transient episodes of spinal cord ischemia. ${ }^{7,8}$ One observational study suggested a clinical benefit of epidural spinal cord cooling in patients who undergo TAAA repair. ${ }^{9}$ Regional hypothermia avoids the systemic complications associated with cooling, such as cardiac arrhythmias, ${ }^{10}$ coagulopathy, ${ }^{11}$ and an increased rate of postoperative infection. ${ }^{12}$ To date, no data are available regarding the influence of regional hypothermia on spinal cord function monitoring with tc-MEPs.

We investigated in pigs the influence of moderate subdural cooling on the time between the onset of spinal cord ischemia and the detection by tc-MEPs. In addition, we investigated the effect of progressive subdural cooling on myogenic tc-MEP signals.

\section{Material and methods}

Animal care and all procedures were performed in compliance with The National Guidelines for Care of Laboratory Animals in the Netherlands. The study protocol was approved by the Animal Research Committee of the Academic Hospital at the University of Amsterdam, the Netherlands. Six female domestic pigs, each weighing 45 to $55 \mathrm{~kg}$, were studied.

Anesthesia. Anesthetics used in this experiment have no major effect on tc-MEP responses and are also used in our clinic for tc-MEP-guided TAAA repair. Ketamine $(15 \mathrm{mg} / \mathrm{kg}$, intramuscularly) was used as premedication. Anesthesia was induced with $2.0 \%$ isoflurane by mask in a mixture of $50 \%$ oxygen in nitrous oxide. After induction, 2 intravenous lines (18-gauge) were introduced in ear veins. The animals received sufentanil $15 \mu \mathrm{g} / \mathrm{kg}$ and clonidine $2 \mu \mathrm{g} / \mathrm{kg}$. Isoflurane was discontinued, and anesthesia was maintained with infusion of ketamine $15 \mathrm{mg} / \mathrm{kg} / \mathrm{h}$, sufentanil $5 \mu \mathrm{g} / \mathrm{kg} / \mathrm{h}$, clonidine $1 \mu \mathrm{g} / \mathrm{kg} / \mathrm{h}$, and nitrous oxide (60\%). Animals were intubated and ventilated with intermittent positive-pressure ventilation. Ventilation was adjusted to maintain an end-tidal carbon dioxide between 4.8 to $5.3 \mathrm{kPa}(36-40 \mathrm{~mm} \mathrm{Hg})$ throughout the experiment. The adequacy of ventilation was confirmed by blood gas analysis at $37^{\circ} \mathrm{C}$. Arterial blood pressure was measured with a catheter placed into the axillary artery and central venous pressure by means of a catheter advanced through the right jugular vein into the superior caval vein. Electrocardiogram, central venous pressure, mean arterial pressure, end-tidal carbon dioxide, and nasopharyngeal temperature were monitored continuously. Fluids were substituted by Ringer's lactate solution, as required.

Tc-MEP monitoring technique. Tc-MEPs were evoked with a multipulse transcranial electrical stimulator (Digitimer D 185 cortical stimulator; Digitimer Ltd, Welwyn Garden City, United Kingdom). The stimuli were applied to the scalp with 4 needle electrodes, with a train of 5 pulses. The interstimulus interval between pulses was $2.0 \mathrm{~ms}$. The anode was placed at the occiput; the cathode consisted of 3 interconnected cathodes placed behind the ears, in the mastoid bone, and in the soft palate. Compound muscle action potentials were recorded from the skin over the quadriceps muscles and foreleg muscles with adhesive gel $\mathrm{Ag} / \mathrm{AgCl}$ electrodes (Fig 1). The signals were amplified 5000 to 20,000 times (adjusted to obtain maximum vertical resolution) and filtered between 30 and $1500 \mathrm{~Hz}$. Data acquisition, processing, and analysis were performed on a computer with an analog-todigital converter and software written in the LabVIEW programming environment (National Instruments, Austin, Tex). Tc-MEPs were recorded at a stimulus intensity of $10 \%$ above the level that produced maximal tc-MEP responses, typically 400 to $500 \mathrm{~V}$. Tc-MEP amplitude was defined as the maximum peak-to-peak distance in millivolts of the compound muscle action potential, and latency was defined as the time between transcranial stimulation and the first negative deflection of the compound muscle action potential. A $25 \%$ intraanimal variation of tc-MEP amplitude was accepted as normal, in agreement with tc-MEP analysis during TAAA repairs in our clinic. ${ }^{5}$ Baseline tc-MEP amplitude and latencies were assessed during laparotomy by averaging 5 consecutive responses. Ischemic spinal cord dysfunction was defined as an amplitude decrease below $25 \%$ of baseline val- 


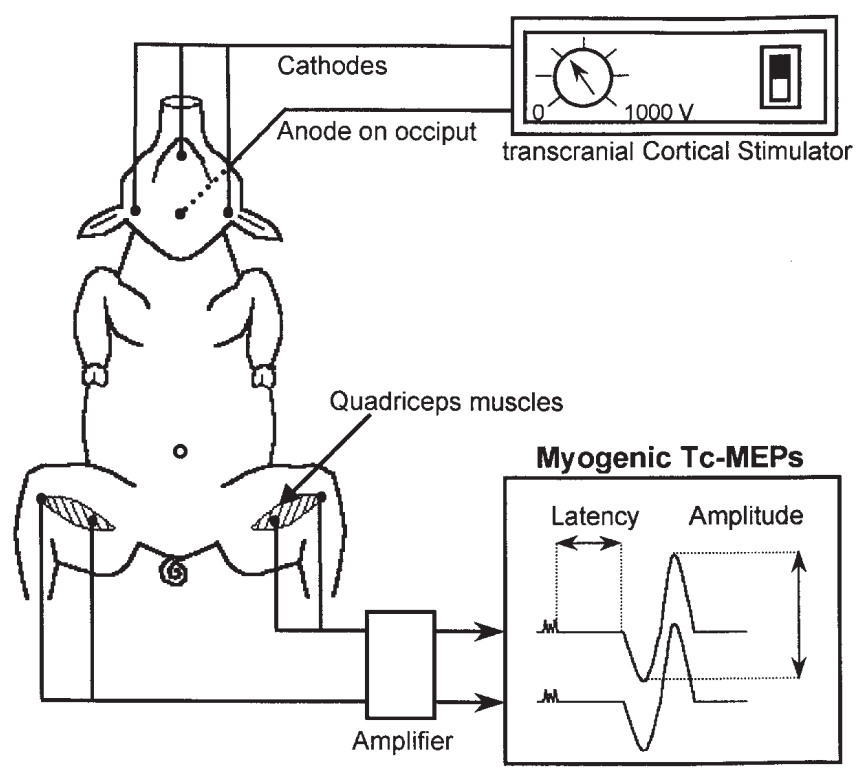

Fig 1. Schematic representation of tc-MEP recording in the experimental animal (ventral view).

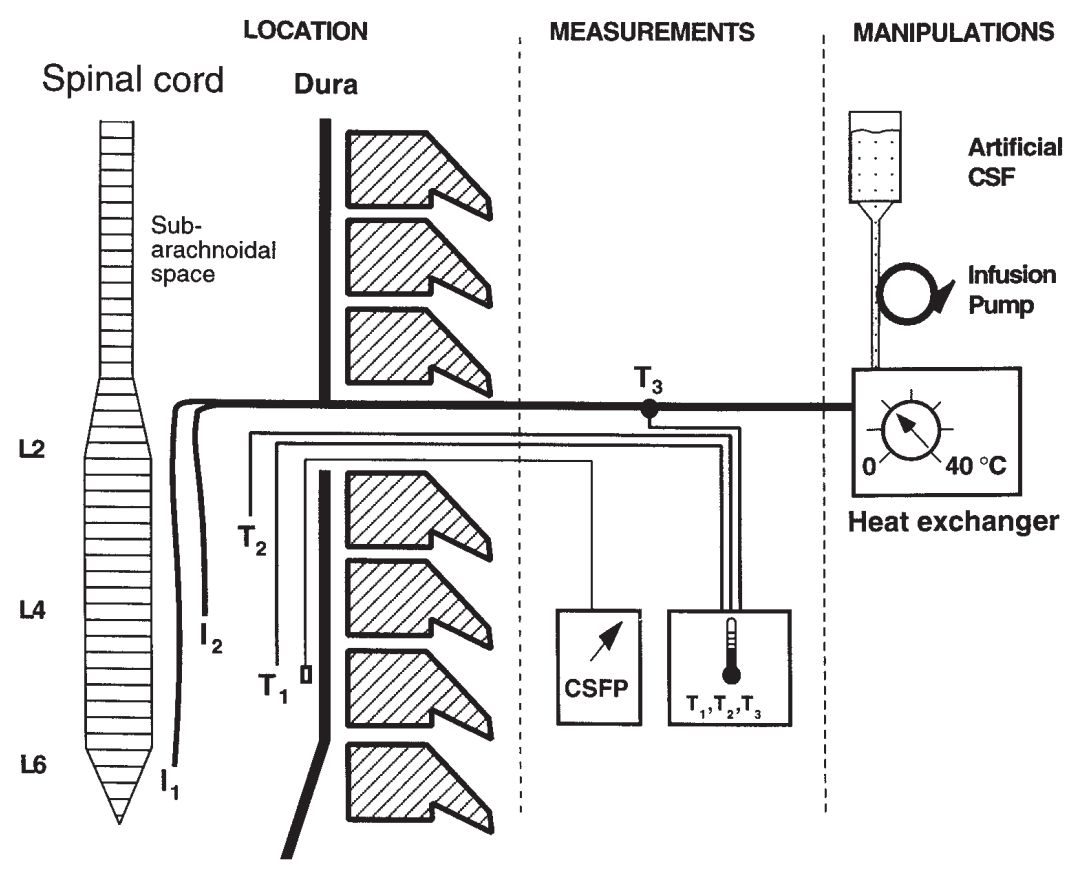

Fig 2. Identification of a set of critical segmental arteries. Clamps are placed on individual segmental arteries in a caudal-to-cranial direction every 5 minutes, until spinal cord ischemia is detected with tc-MEPs. This example demonstrates detection of spinal cord ischemia when the L6, L5, L4, L3, and L2 segmental arteries are clamped. CSFP, Cerebrospinal fluid pressure.

ues. Because of interanimal variation, amplitudes are given as percentages of baseline values. Tc-MEP amplitude and latencies of the left leg were used for data analysis. Tc-MEP responses of forepaw muscles were used to recognize potential systemic or technical causes of tc-MEP decrease.
Regional spinal cord cooling. The aim was to cool the lumbar spinal cord segment containing the hind limb motor neurons while minimizing cerebrospinal fluid (CSF) pressure increases. In pilot experiments we learned that 2 separate inflow catheters were necessary to obtain uniform cooling of 
this segment. A laminectomy at the L2 level and a durotomy assured sufficient outflow and prevented CSF pressure increases above $15 \mathrm{~mm} \mathrm{Hg}$. Two 3F inflow catheters, connected to an infusion pump and heat exchanger, were introduced through the durotomy and advanced caudally. One tip was positioned at the L6 level, and the other was positioned at the L4 level. Another 3F catheter was placed with the tip at the L5 level for CSF pressure measurements. Temperature probes (Subcutaneous Temperature Sensor; Monatherm Inc, St Louis, Mo), connected to a Mon-a-therm model 6510 (Mallinkrodt Medical, Inc, St Louis, Mo), were placed at the L3 and L5 levels; one probe was placed within the inflow catheter approximately $10 \mathrm{~cm}$ before reaching the subarachnoid space (Fig 2). Normal saline solution was used for perfusion. Cooling was performed with a heat exchanger (Hyp 10; Gambro, Lund, Sweden) that was placed between the infusion pump and the perfusion catheters. Perfusate temperature could be varied between $4^{\circ} \mathrm{C}$ and $40^{\circ} \mathrm{C}$.

Spinal cord ischemia. The animals were placed in the right decubitus position. The abdomen was opened through a midline incision, and the viscera were rotated to the right. The left kidney was mobilized and placed to the right, and the aorta, aortic bifurcation, lumbar arteries, and the sacral artery were carefully dissected.

Thereafter, critical segmental arteries were identified by sequentially clamping the lumbar arteries in a caudocranial direction, starting with the L6 artery. After placement of each additional segmental artery clamp, an observation period of 5 minutes was allowed to detect whether ischemic spinal cord dysfunction developed, as evidenced by a tc-MEP amplitude decrease below $25 \%$ of baseline (Fig 3). When tc-MEPs indicated spinal cord ischemia, the presently clamped set of segmental arteries was considered critical for spinal cord blood flow, and the clamps were immediately removed. A period of at least 15 minutes was allowed for the tc-MEP responses to recover completely.

To induce spinal cord ischemia in the subsequent experiments, these clamps were placed simultaneously on the previously defined set of critical segmental arteries.

The influence of moderate subdural hypothermia on spinal cord ischemia detection. The time interval between clamping a set of critical segmental arteries and the onset of spinal cord ischemia was assessed (ischemia detection time) during normothermic perfusion. After the ischemia detection time at normothermia was determined, at least 15 minutes were allowed for the tc-MEP response to return to baseline. At that time, subdural perfusion cooling was started by decreasing the infusate temperature until the CSF temperature reached approximately $28^{\circ} \mathrm{C}$. An inflow rate of $700 \mathrm{~mL} / \mathrm{h}$ was used to reach this target. CSF temperatures were maintained at $28^{\circ} \mathrm{C}$ for 15 minutes. Then, clamping of the set of critical segmental arteries was repeated, and the ischemia detection time was determined at $28^{\circ} \mathrm{C}$. Clamps were removed as soon as ischemia was detected. Perfusion cooling was stopped, and CSF temperature was allowed to increase to $37^{\circ} \mathrm{C}$ spontaneously. Subsequently, a recovery period of at least 30 minutes was regarded after the tc-MEP recovered to baseline values.
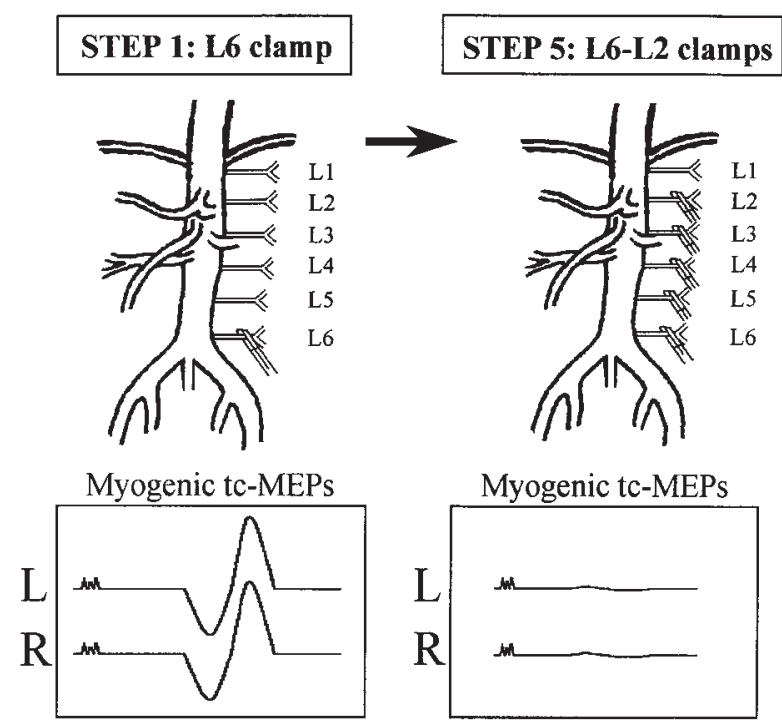

Fig 3. Experimental setup. A laminectomy and durotomy was performed at the L2 level. Inflow catheters are introduced into the subdural space with the tips advanced to the L4 and L6 level. Temperatures are measured at the L5 level (T1) and the L3 level (T2) and within the common afferent perfusate catheter (T3). Subdural CSF pressure is measured at the L5 level.

The influence of progressive subdural hypothermia on tc-MEPs. Finally, the effect of CSF temperature decreases on tc-MEP amplitude and latency was assessed by cooling the perfusate to $4{ }^{\circ} \mathrm{C}$. Tc-MEPs were assessed every minute until tc-MEP amplitude decreased below 25\% of baseline. The relationship between CSF temperature and tc-MEP amplitude and latency was assessed. At the end of the experiment animals were killed by infusion of pentobarbital intravenously.

Statistical analysis. All data are expressed as mean \pm SEM. Differences in ischemia detection time between normothermic and hypothermic conditions were compared with paired $t$ tests. Tc-MEP amplitudes and latencies are presented as medians (+10th and 90th percentiles). The effect of progressive CSF temperature decreases on tc-MEP amplitude and latency was analyzed with regression for each individual animal. The mean regression equation was calculated as a result of the unweighted mean of the regression coefficients of each animal.

\section{Results}

Mean arterial pressure was $84 \pm 4 \mathrm{~mm} \mathrm{Hg}$ during laparotomy and $87 \pm 6 \mathrm{~mm} \mathrm{Hg}$ when sets of critical segmental arteries were clamped at moderate subdural cooling. CSF pressures were compared during laparotomy, at moderate subdural cooling, and at maximal perfusion rates and were $7.9 \pm 2.3 \mathrm{~mm} \mathrm{Hg}, 13.3 \pm 3.5$ $\mathrm{mm} \mathrm{Hg}$, and $14.6 \pm 4.0 \mathrm{~mm} \mathrm{Hg}$, respectively $(P=.2 ; P$ $=.2$, and $P=.3$ ). As a result, spinal cord perfusion pres- 


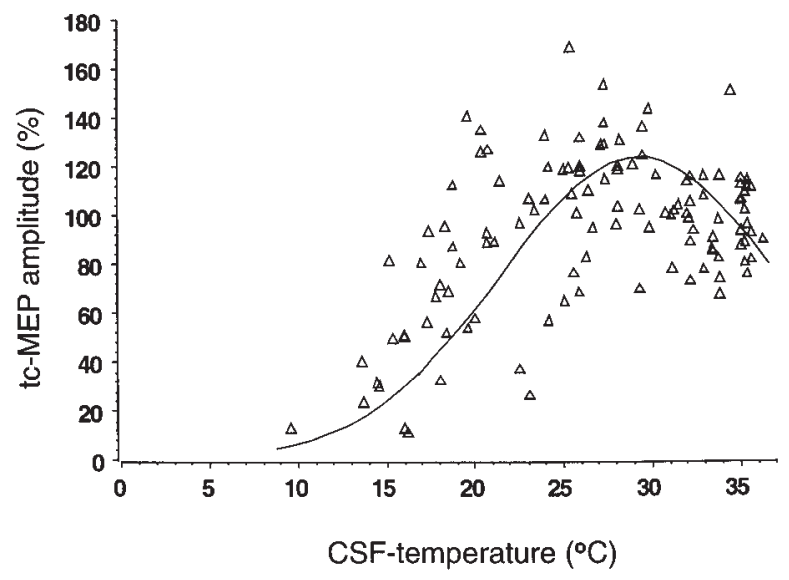

Fig 4. The influence of a progressive CSF temperature decrease on tc-MEP amplitudes. Raw data are shown as triangles. The average regression curve (continuous line) shows an initial increase with a maximum at $29.6^{\circ} \mathrm{C}$ and, thereafter, a progressive tc-MEP amplitude decrease.

sures remained at $72.9 \pm 6.8 \mathrm{~mm} \mathrm{Hg}$ in all animals during the experiment. Nasopharyngeal temperatures decreased during the experiment from $37.8^{\circ} \mathrm{C} \pm 0.4^{\circ} \mathrm{C}$ to $36.6^{\circ} \mathrm{C} \pm 0.2^{\circ} \mathrm{C}$.

Reproducible tc-MEPs could be recorded in all animals. Supramaximal stimuli were obtained in every animal by the use of 400 - to $500-\mathrm{V}$ stimulation intensity. Response amplitude was $3707 \mu \mathrm{V}(3182-4569 \mu \mathrm{V})$ at baseline. Baseline latency was $16.8 \mathrm{~ms}$ (15.7-17.7 ms). In animal 4, tc-MEP-amplitudes of the left leg decreased after introduction of the subdural catheters, possibly as a result of nerve root compression by 1 of the catheters. In this animal, amplitudes recorded from the right leg were used for analysis.

Six lumbar arteries were present in each animal. During sequential clamping of these arteries, starting from the L6 level in a cranial direction, 1 animal showed tc-MEP evidence of spinal cord ischemia after the L6-L3 level was clamped; 4 animals showed tcMEP evidence of spinal cord ischemia when the L6-L2 arteries were clamped, and 1 animal showed tc-MEP evidence of spinal cord ischemia after the L6-L1 arteries were clamped.

The influence of moderate subdural hypothermia on spinal cord ischemia detection. No significant difference was observed between the onset of spinal cord ischemia and a tc-MEP amplitude decrease below 25\% at normothermic perfusion or moderate subdural perfusion cooling $\left(28.3^{\circ} \mathrm{C} \pm 0.7^{\circ} \mathrm{C}\right)$. Tc-MEPs detected spinal cord ischemia within $3.2 \pm 0.5$ and $3.8 \pm 0.9$ minutes, respectively $(P=.6)$. Tc-MEPs of the

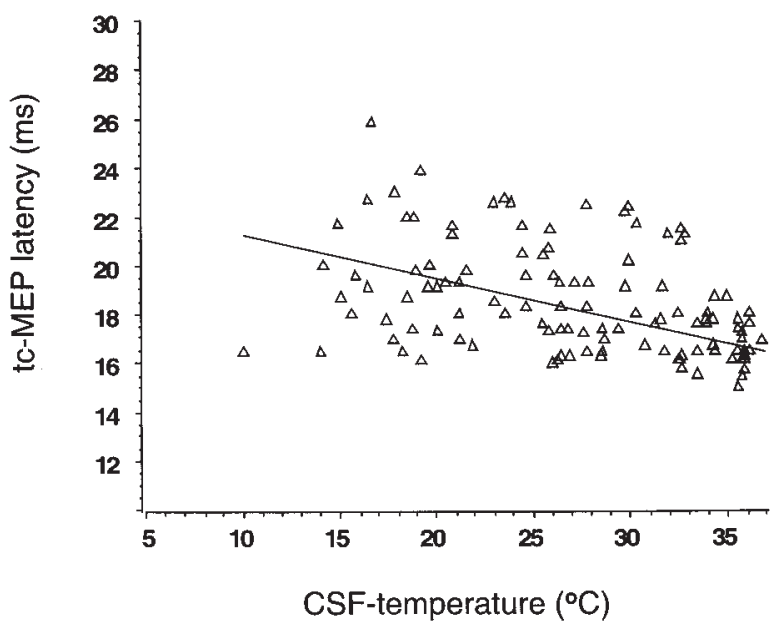

Fig 5. The influence of a progressive CSF temperature decrease on tc-MEP latencies. Raw data are shown as triangles. The average regression curve (continuous line) shows a linear increase when CSF temperatures decrease.

forepaws remained at $89.6 \% \pm 2.4 \%$ during this part of the experiment. At a perfusion rate of $700 \mathrm{~mL} / \mathrm{h}, \mathrm{CSF}$ temperatures of $28^{\circ} \mathrm{C}$ were reached within $15.7 \pm 4.9$ minutes. Average inflow temperatures of $23.7^{\circ} \mathrm{C} \pm$ $1.4^{\circ} \mathrm{C}$ were necessary to reach this target. After the arterial clamps were removed, tc-MEP amplitudes rapidly returned to baseline in all animals.

The influence of progressive subdural hypothermia on tc-MEPs. After the start of progressive CSF cooling, tc-MEP amplitudes initially increased in all animals. Below $30^{\circ} \mathrm{C}$, tc-MEP amplitudes decreased progressively, and amplitudes decreased to values below $25 \%$ of baseline at an average CSF temperature of $14.0^{\circ} \mathrm{C} \pm 1.1^{\circ} \mathrm{C}$. The mean regression equation for $\log$ (tc-MEP amplitude) was $-2.2+0.47 \cdot$ CSF temperature $-0.008 \cdot \mathrm{CSF}$ temperature ${ }^{2}$. The variances for the intercept, CSF temperature and CSF temperature ${ }^{2}$ were $-2.2,0.17$ and 0.002 , respectively. The maximum of the quadratic function was at $29.6^{\circ} \mathrm{C}\left(25^{\circ} \mathrm{C}-34^{\circ} \mathrm{C}\right)$. Fig 4 shows the raw tc-MEP amplitude data and the average regression curve. The equation predicts a tc-MEP amplitude decrease below $25 \%$ at $15.5^{\circ} \mathrm{C}$. For $\log ($ tcMEP-latency), the mean regression equation was 3.1 $-0.009 \cdot$ CSF temperature, with a variance of 0.2 for the intercept and 0.005 for the CSF temperature. Fig 5 shows raw tc-MEP latencies and the mean regression curve. Average inflow rates of $966 \pm 20 \mathrm{~mL} / \mathrm{h}$ at $4{ }^{\circ} \mathrm{C}$ were necessary to reach CSF temperatures that resulted in tc-MEP loss. At these perfusion rates, CSF pressures remained below $15 \mathrm{~mm} \mathrm{Hg}$. In 1 animal, CSF temperature did not decrease below $22^{\circ} \mathrm{C}$, despite the maxi- 
mum pump flow rate of $999 \mathrm{~mL} / \mathrm{h}$ and tc-MEP amplitude remained at $25.7 \%$ of baseline. Tc-MEP amplitudes of the forepaws remained at an average of $92.5 \%$ $\pm 4.8 \%$ of baseline during this part of the experiment. After the infusion pump was stopped, CSF temperatures and tc-MEP amplitudes increased to baseline within 10 minutes in all animals.

\section{Discussion}

Moderate subdural hypothermia did not increase the time between the onset of spinal cord ischemia and the detection of this state with tc-MEPs in this porcine experiment. These data suggest that myogenic tc-MEPs can rapidly detect spinal cord ischemia when moderate regional cooling protocols are applied to increase spinal cord ischemia tolerance during aortic clamping.

At $28^{\circ} \mathrm{C}$, there is considerable protection against neuronal damage after transient episodes of ischemia. ${ }^{13}$ Because hypothermia decreases the ischemia-induced release of excitatory neurotransmitter release ${ }^{14}$ and slows metabolic rate, ${ }^{15,16}$ we hypothesized that motor neuron function during spinal cord ischemia might be preserved when moderate subdural hypothermia is applied, possibly delaying tc-MEPs detection of spinal cord ischemia at this CSF temperature. However, at $28^{\circ} \mathrm{C}$ we did not observe an increased time between the onset of spinal cord ischemia and detection with tcMEPs. These results are in accordance with observations by Svensson and colleagues, ${ }^{17}$ who investigated spinal cord motor-evoked potentials during aortic clamping in pigs. Infusion of cold liquid into the occluded aorta did not preclude a rapid evoked potential decrease to values of approximately $25 \%$ of baseline, when the aortic segment was clamped. However, perispinal temperatures were not assessed during this experiment. Apparently, spinal cord ischemia during moderate subdural hypothermia results in a loss of synaptic activity as rapidly as during normothermia. These results do not imply, however, that spinal cord protection will not be achieved at this CSF temperature.

During the second part of the experiment, where progressive CSF cooling was performed without segmental artery clamping, an initial tc-MEP amplitude increase was followed by a decrease in all animals, although tc-MEP latencies increased progressively.

Hypothermia induces several neurophysiologic changes, including decreases in resting potential, decreases in potential amplitude, an increase in duration of the action potential, reduction of nerve conduction velocity, and depression of synaptic transmission. ${ }^{18-22}$ Ultimately, severe hypothermia will result in complete suppression of both axonal and synaptic transmission. However, in the present study, an initial tc-MEP amplitude increase preceded the eventual decrease. This phenomenon was also observed in cats when neurogenic corticomotor-evoked potentials and SSEPs were measured during progressive hypothermia. ${ }^{23}$ This hyperresponsiveness during moderate cooling is thought to be the result of an increased release of the neurotransmitter in the synaptic space because of longer duration of the action potential. ${ }^{19,24}$ Increased duration of individual potentials may even result in summation. $^{25}$ The tc-MEP amplitude decreases and latency increases observed when CSF temperatures were further decreased in this experiment are consistent with clinical reports concerning the influence of systemic hypothermia on SSEPs. ${ }^{26,27}$ Progressive cooling could mimic SSEP evidence of spinal cord ischemia. In our study, tc-MEP amplitudes below $25 \%$ of baseline amplitudes were observed at CSF temperatures of $14.0^{\circ} \mathrm{C} \pm 1.1^{\circ} \mathrm{C}$. These results imply that progressive subdural hypothermia could also mimic tcMEP evidence of spinal cord ischemia, rendering spinal cord monitoring unreliable at these CSF temperatures. In addition, tc-MEP latencies increased during moderate spinal cord hypothermia. However, tc-MEP potential latency is not considered to be a sensitive ischemia predictor, ${ }^{5}$ and these findings may therefore have less clinical significance.

In our institution, tc-MEP monitoring is an integral part in the selective application of spinal cord protective measures and guides strategies that improve spinal cord perfusion (ie, distal aortic perfusion, reattachment of segmental arteries, and maintaining adequate proximal and distal arterial pressure). 5,6 The protective qualities of regional spinal cord hypothermia have been described extensively in experimental studies and could, theoretically, offer spinal cord protection during prolonged aortic clamping. Indeed, a clinical series suggested a benefit in 70 patients who underwent surgical repair for type I and II TAAA, when epidural cooling during aortic clamping resulted in an overall incidence of neurologic deficits of $2.9 \%$ only. ${ }^{9}$ With the use of this technique, systemic complications (such as increased cardiac excitability, ${ }^{10}$ coagulation defects ${ }^{28}$ and an increased risk for postoperative wound infections) ${ }^{12}$ can be avoided. When the data from these experiments are applicable in the human situation, protection of the spinal cord during prolonged aortic crossclamp episodes could possibly be performed with regional spinal cord moderate hypothermia, although accurate detection of spinal cord ischemia remains possible. However, at CSF temperatures below $25^{\circ} \mathrm{C}$, tcMEP monitoring might become unreliable because of 
significant decreases in the tc-MEP response that may be indistinguishable from spinal cord ischemia.

The experimental sequence used in the present study had several disadvantages. First, spinal cord ischemia was induced 3 times in the same animal, which might have influenced later tc-MEP recordings. The induction of a relatively short period of neuronal ischemia might generate tolerance or increase sensitivity to a subsequent period of spinal cord ischemia. This would only be of influence if neuronal survival was the end point. However, in the present study neuronal transmission was assessed. Second, the influence of regional hypothermia was assessed after these episodes of ischemia, which is arguable. We opted to follow this sequence because we were uncertain whether the assessment of the influence of deep regional hypothermia on tc-MEP characteristics, before the determination of the spinal cord ischemia detection time at different CSF temperatures, might actually preclude the latter. Nevertheless, tc-MEP responses recovered to baseline values after each manipulation, suggesting that motor neuron function was not permanently impaired.

In conclusion, the results of this study suggest that myogenic tc-MEPs can be recorded reliably during moderate subdural hypothermia in pigs. Detection of acute spinal cord ischemia with tc-MEPs is not delayed at regional CSF temperatures of $28^{\circ} \mathrm{C}$. At this temperature, tc-MEP amplitudes are increased. When CSF temperature is decreased further, a progressive amplitude decrease and latency increase occurs.

We thank Marjolein Porsius for monitoring the tc-MEPs; Siem Hijsterkamp (Department of Biostatistics, Academic Medical Center, University of Amsterdam, The Netherlands) for his statistical insights; and Lameris (Veenendaal, The Netherlands) for providing the temperature probes.

\section{REFERENCES}

1. Crawford ES, Crawford JL, Safi HJ, et al. Thoracoabdominal aortic aneurysms: preoperative and intraoperative factors determining immediate and long-term results of operations in 605 patients. J Vasc Surg 1986;3:389-404.

2. Davison JK, Cambria RP, Vierra DJ, Columbia MA, Koustas G. Epidural cooling for regional spinal cord hypothermia during thoracoabdominal aneurysm repair. J Vasc Surg 1994;20:304-10.

3. Svensson LG, Hess KR, Coselli JS, Safi HJ. Influence of segmental arteries, extent, and atriofemoral bypass on postoperative paraplegia after thoracoabdominal aortic operations. J Vasc Surg 1994;20:255-62.

4. Crawford ES, Mizrahi EM, Hess KR, Coselli JS, Safi HJ, Patel VM. The impact of distal aortic perfusion and somatosensory evoked potential monitoring on prevention of paraplegia after aortic aneurysm operation. J Thorac Cardiovasc Surg 1988;95:357-67.

5. Haan de P, Kalkman CJ, de Mol BA, Ubags LH, Veldman DJ, Jacobs MJ. Efficacy of transcranial motor-evoked myogenic potentials to detect spinal cord ischemia during operations for thoracoabdominal aneurysms. J Thorac Cardiovasc Surg 1997; 113:87-100.

6. Jacobs MJ, Meylaerts SA, de Haan P, de Mol BA, Kalkman CJ. Strategies to prevent neurologic deficit based on motor-evoked potentials in type I and II thoracoabdominal aortic aneurysm repair. J Vasc Surg 1999;29:48-59.

7. Marsala M, Vanicky I, Galik J, Radonak J, Kundrat I, Marsala J. Panmyelic epidural cooling protects against ischemic spinal cord damage. J Surg Res 1993;55:21-31.

8. Vanicky I, Marsala M, Galik J, Marsala J. Epidural perfusion cooling protection against protracted spinal cord ischemia in rabbits. J Neurosurg 1993;79:736-41.

9. Cambria RP, Davison JK, Zannetti S, et al. Clinical experience with epidural cooling for spinal cord protection during thoracic and thoracoabdominal aneurysm repair. J Vasc Surg 1997;25:234-41.

10. Okada M. The cardiac rhythm in accidental hypothermia. J Electrocardiol 1984;17:123-8.

11. Patt A, McCroskey BL, Moore EE. Hypothermia-induced coagulopathies in trauma. Surg Clin North Am 1988;68:775-85.

12. Kurz A, Sessler DI, Lenhardt R. Perioperative normothermia to reduce the incidence of surgical-wound infection and shorten hospitalization: study of wound infection and temperature group. N Engl J Med 1996;334:1209-15.

13. Marsala M, Vanicky I, Yaksh TL. Effect of graded hypothermia ( 27 degrees to 34 degrees C) on behavioral function, histopathology, and spinal blood flow after spinal ischemia in rat. Stroke 1994;25:2038-46.

14. Rokkas CK, Cronin CS, Nitta T, et al. Profound systemic hypothermia inhibits the release of neurotransmitter amino acids in spinal cord ischemia. J Thorac Cardiovasc Surg 1995;110:27-35.

15. Allen BT, Davis CG, Osborne D, Karl I. Spinal cord ischemia and reperfusion metabolism: the effect of hypothermia. J Vasc Surg 1994;19:332-9.

16. Michenfelder JD, Milde JH. The relationship among canine brain temperature, metabolism, and function during hypothermia. Anesthesiology 1991;75:130-6.

17. Svensson LG, Crawford ES, Patel V, McLean TR, Jones JW, DeBakey ME. Spinal oxygenation, blood supply localization, cooling, and function with aortic clamping. Ann Thorac Surg 1992;54:74-9.

18. Benita M, Conde H. Effects of local cooling upon conduction and synaptic transmission. Brain Res 1972;36:133-51.

19. Bindman LJ, Lippold OJC, Redfearn JWT. Comparison of the effects on electrocortical activity of general body cooling and local cooling of the surface of the brain. Electroencephalogr Clin Neurophysiol 1963;15:238-45.

20. Katz B, Miledi R. The effect of temperature on the synaptic delay at the neuromuscular junction. J Physiol 1965;181:656-70.

21. Klee MR, Pierau FK, Faber DS. Temperature effects on resting potential and spike parameters of cat motoneurons. Exp Brain Res 1974;19:478-92.

22. Weight FF, Erulkar SD. Synaptic transmission and effects of temperature at the squid giant synapse. Nature 1976;261:720-2.

23. Browning JL, Heizer ML, Baskin DS. Variations in corticomotor and somatosensory evoked potentials: effects of temperature, halothane anesthesia, and arterial partial pressure of $\mathrm{CO}_{2}$. Anesth Analg 1992;74:643-8.

24. Lundberg A. Potassium and the differential thermosensitivity of membrane potential, spike and negative after-potential in 
mammalian A and C fibers. Acta Physiol Scand Suppl 1948;50: 1-67.

25. Andersen P, Gjerstad L, Pasztor E. Effect of cooling on synaptic transmission through the cuneate nucleus. Acta Physiol Scand 1972;84:433-47.

26. Markand ON, Warren CH, Moorthy SS, Stoelting RK, King RD. Monitoring of multimodality evoked potentials during open heart surgery under hypothermia. Electroencephalogr Clin Neurophysiol 1984;59:432-40.

27. Rheineck Leyssius AT, Kalkman CJ, Bovill JG. Influence of moderate hypothermia on posterior tibial nerve somatosensory evoked potentials. Anesth Analg 1986;65:475-80.

28. Rohrer MJ, Natale AM. Effect of hypothermia on the coagulation cascade. Crit Care Med 1992;20:1402-5.

\section{ON THE MOVE?}

Don't miss a single issue of the journal! To ensure prompt service when you change your address, please photocopy and complete the form below.

Please send your change of address notification at least six weeks before your move to ensure continued service. We regret we cannot guarantee replacement of issues missed due to late notification.

\section{JOURNAL TITLE:}

Fill in the title of the journal here.

\section{OLD ADDRESS:}

Affix the address label from a recent issue of the journal here.

\section{NEW ADDRESS:}

Clearly print your new address here.

Name

Address

City/State/ZIP
COPY AND MAIL THIS FORM TO:

Periodical Subscription Services

Mosby, Inc.

11830 Westline Industrial Dr.

St. Louis, MO 63146-3318
OR FAX TO:

314-432-1158

N/ Mosby
OR PHONE:

1-800-453-4351

Outside the U.S., call

314-453-4351 